\title{
Динамика расселения населения в зоне Российско-Казахстанского приграничья
}

\author{
Р.Ш. Ахметов ${ }^{1}$ И. Ю. Филимонова ${ }^{2} \bowtie$, Н.И. Ахметова ${ }^{3}$ \\ ${ }^{I}$ Оренбургский государственный университет, Российская Федерация \\ (460018, г. Оренбург, просп. Победы, д. 13) \\ ${ }^{2}$ Институт степи Уральского отделения Российской академии наук - обособленное структурное \\ подразделение Федерального государственного бюджетного учреждения науки Оренбургский \\ федеральный исследовательский иентр Уральского отделения Российской академии наук, \\ Российская Федераиия (460000, г. Оренбург, ул. Пионерская, д. 11) \\ ${ }^{3}$ Оренбургский государственный педагогический университет, Российская Федерация \\ (460014, г. Оренбург, ул. Советская, д. 19)
}

\begin{abstract}
Аннотация: Цель: пространственный анализ влияния новых государственных границ, возникших в результате распада СССР, на процесс расселения населения по обе стороны государственной границы.

Информационной базой исследования стала единая географическая база данных переписей населения на территории Оренбургской области и приграничных регионов Казахстана.

Сравнительный анализ показал значительное сходство в динамике этих показателей между пограничной зоной и территорией региона в целом. Результаты исследования не подтвердили гипотезу об оттоке населения из пограничной зоны и «скелетизацию» сети расселения в результате воздействия барьерной функции государственной границы и, как следствие, ухудшение условий экономической деятельности и затрудненности социальных контактов. Ряд крупных городов, главных рек региона и других привлекательных для поселения объектов, расположенных в приграничной зоне, сводят к минимуму и маскируют эффект границы. Таким образом, исследование на примере российско-казахстанской границы показывает, что новое российское приграничье не оказывает заметного угнетающего воздействия на структуру расселения населения. Кроме того, процессы, происходящие в расселении по обе стороны государственной границы, как правило, сходны и трансграничны.
\end{abstract}

Ключевые слова: расселение населения, динамика расселения, приграничье.

Источник финансирования: Работа выполнена в рамках государственного задания AAAA-A17-117012610022-5.

Для цитирования: Ахметов Р.Ш., Филимонова И.Ю., Ахметова Н.И. Динамика расселения населения в зоне Российско-Казахстанского приграничья // Вестник Воронежского государственного университета. Серия: География. Геоэкология, 2020, №2, с. 29-34. DOI: https://doi.org/10.17308/geo.2020.2/2882

\section{ВВЕДЕНИЕ}

Самостоятельной и перспективной проблемой для исследования процесса расселения населения является, по нашему мнению, влияние на него новых государственных границ, возникших в результате распада СССР. Единое и тесно связанное экономическое, социальное, инфраструктурное пространство в начале 1990-х годов было рассечено, что положило начало во многом болезненному процессу формирования самостоятельных государственных организмов. Территориальные эффекты и последствия этого процесса нуждаются в детальном анализе.

Изучением фактора границы в социально-экономической сфере и, в частности, его влиянием на расселение занимаются ученые разных направлений, в том числе и географы. Значительная часть работ посвящена изучению границ на постсоветском пространстве. Рассматриваются различные

(С) Ахметов Р.Ш., Филимонова И.Ю., Ахметова Н.И., 2020

$\triangle$ E-mail: filimo-irina@yandex.ru

Контент доступен под лицензией Creative Commons Attribution 4.0 License. 
Показатели динамики сельского расселения в Оренбургско-Казахстанском приграничье [Table. Indicators of rural resettlement dynamics in the Orenburg-Kazakhstan border area]

\begin{tabular}{|c|c|c|c|c|c|c|}
\hline \multirow[b]{2}{*}{ Показатель / Indicator } & \multirow{2}{*}{$\begin{array}{c}\text { Год } \\
\text { переписи / } \\
\text { Year of } \\
\text { census }\end{array}$} & \multicolumn{4}{|c|}{ Буферные зоны / Buffer zones } & \multirow{2}{*}{$\begin{array}{c}\text { Область в } \\
\text { целом / } \\
\text { The entire } \\
\text { region }\end{array}$} \\
\hline & & $\begin{array}{c}5 \mathrm{\kappa м} / \\
5 \mathrm{~km}\end{array}$ & $\begin{array}{c}10 \mathrm{kM} / \\
10 \mathrm{~km}\end{array}$ & $\begin{array}{c}20 \mathrm{kм} / \\
20 \mathrm{~km}\end{array}$ & $\begin{array}{c}50 \mathrm{\kappa м} / \\
50 \mathrm{~km}\end{array}$ & \\
\hline \multirow{3}{*}{$\begin{array}{l}\text { Доля сельского } \\
\text { населения (\%) / } \\
\text { Percentage of rural } \\
\text { population (\%) }\end{array}$} & 1989 & 3,6 & 6,2 & 12,5 & 33,6 & 100 \\
\hline & 2002 & 3,7 & 6,3 & 12,4 & 32,0 & 100 \\
\hline & 2010 & 3,4 & 5,9 & 11,6 & 32,7 & 100 \\
\hline \multirow{3}{*}{$\begin{array}{l}\text { Доля сельских } \\
\text { населенных пунктов } \\
\text { (\%) / Percentage of } \\
\text { rural settlements (\%) }\end{array}$} & 1989 & 3,1 & 5,8 & 10,5 & 28,7 & 100 \\
\hline & 2002 & 3,1 & 5,7 & 10,4 & 28,6 & 100 \\
\hline & 2010 & 3,2 & 5,6 & 10,4 & 29,3 & 100 \\
\hline \multirow{3}{*}{$\begin{array}{l}\text { Средняя людность } \\
\text { сельского } \\
\text { населенного пункта } \\
\text { (чел.) / Average } \\
\text { population of a rural } \\
\text { settlement (people) }\end{array}$} & 1989 & 602 & 553 & 618 & 606 & 518 \\
\hline & 2002 & 641 & 595 & 643 & 607 & 542 \\
\hline & 2010 & 543 & 518 & 554 & 556 & 497 \\
\hline \multirow{3}{*}{$\begin{array}{l}\text { Плотность сельского } \\
\text { населения } \\
\text { (чел./кв.км) / Rural } \\
\text { population density } \\
\text { (people / square km) }\end{array}$} & 1989 & 4,3 & 4,0 & 4,4 & 5,3 & 7,3 \\
\hline & 2002 & 4,5 & 4,2 & 4,5 & 5,2 & 7,5 \\
\hline & 2010 & 3,7 & 3,4 & 3,7 & 4,7 & 6,6 \\
\hline
\end{tabular}

аспекты: воздействие границ на коммуникацию населения в западных областях России, изучение социокультурного влияния соседних стран на жизнь населения пограничной территории северо-запада России. Популярны темы, связанные с анализом трансграничных миграций $[2,5,7]$, приграничной конфликтологии [4] и влияния границы на расселение населения $[3,6,8]$. Географических работ, изучающих население по обе стороны границы крайне мало.

\section{МЕТОДИКА ЭКСПЕРИМЕНТА}

Изучение влияния границы и выявление эффектов приграничности требует конкретизации и формализации понятия «приграничная территория». Несмотря на большое внимание в последнее время к исследованиям приграничных и трансграничных территорий критерии их выделения остаются недостаточно четкими [1].

Изучение влияния «нового» приграничья на расселение осложнено тем, что одновременно с ним на расселение воздействует также ряд других процессов и явлений. Например, происходящая в настоящее время поляризация географического пространства и концентрация населения на территориях с выгодным географическим положением и благоприятными условиями жизни и хозяйственной деятельности под влиянием перехода к рыночным отношениям. Вследствие этого характер динамики расселения на отдельных участках и локальных фрагментах приграничных зон, а также по разные стороны границы может существенно различаться. В связи с этим интерес представляет сопряженный анализ сдвигов в расселении в единой зоне приграничья, включающей территории по обе стороны границы.

Территориальным объектом нашего исследования является участок российско-казахстанского приграничья в пределах территории Оренбургской области и трех сопредельных с ней областей Республики Казахстан. Для проведения анализа была создана единая географическая база данных на Оренбургскую область и сопредельные области Казахстана: Западно-Казахстанскую, Актюбинскую и Костанайскую. Определенную трудность для сопряженного анализа динамики расселения создает несогласованность проведения переписей населения в обеих странах, из материалов которых можно получить наиболее подробные и точно локализованные данные.

На первом этапе анализа нами были сопоставлены усредненные данные в целом по Оренбургс- 
кой области и территории приграничной зоны о динамике плотности сельского населения, динамике плотности сети сельских населенных пунктов и их средней людности (таблица). Сравнительный анализ показал существенное сходство в динамике этих показателей между приграничьем и территорией региона в целом. Можно отметить более низкую плотность сельского населения. Она начинает расти только за пределами 20-ти километровой приграничной полосы. Ожидавшийся нами выраженный отток населения из приграничной зоны и «скелетизация» сети расселения в результате действия барьерной функции государственной границы и, как следствие, ухудшения условий экономической деятельности и затруднения социальных контактов выявлены не были. Вероятно, это связано с тем, что в пределах приграничной территории располагается ряд крупных городов, основные реки региона и другие привлекательные для расселения объекты. В результате этого эффект границы нивелируется и маскируется.

Таблица составлена авторами по результатам переписей населения Оренбургской области 2002 года и 2010 года и Республики Казахстан 1999 года, 2009 года.

Для более детального изучения влияния границы на расселение, изучение его возможных локальных эффектов нами был использован инструмент анализа «горячих» и «холодных» точек из арсенала геоинформационных технологий. Он позволяет выявить статистически значимые пространственные кластеры высоких значений («горячих» точек) и низких значений («холодных» точек) тех или иных параметров пространственных объектов. Инструмент рассчитывает значения и анализирует каждый объект единого набора данных в контексте соседних объектов и отвечает на вопрос, в какой области пространства кластеризуются объекты с высокими или низкими значениями явления, интересующего исследователя. В рамках данного анализа объект с высоким значением не считается статистически значимой «горячей» точкой. Чтобы стать статистически существенной «горячей» точкой, пространственный объект с высоким значением должен располагаться рядом с другими объектами с также высокими значениями анализируемого показателя. Таким образом, в ходе анализа исключаются случайные выбросы значений исследуемого явления и выявляются не отдельные объекты, а кластеры объектов со сходными значениями рассматриваемых атрибутов. Использование этого инструмента анализа в нашем слу- чае позволяет выявить тенденции и сдвиги в размещении населения и системе расселения.

Исходя из конкретных условий российско-казахстанского приграничья, для проведения нашего исследования мы остановились на зоне шириной 50 км с каждой стороны границы.

Для того, чтобы сделать показатели сопоставимыми и провести сопряженный пространственный анализ приграничных территорий России и Казахстана, данные о динамике численности населения населенных пунктов по казахстанской стороне границы были рассчитаны в среднем за год для периода между переписями 1999 и 2009 годы. Для Оренбургской области использованы данные о среднегодовой динамике численности населения населенных пунктов в период между переписями 2002 и 2010 годы.

\section{ОБСУЖДЕНИЕ РЕЗУЛЬТАТОВ}

Картографирование материалов переписей населения позволило выявить «горячие» точки, маркирующие зоны, соответственно, высокой и меньшей положительной динамики расселения, и «холодные» точки - зоны более или менее выраженной депрессии и сокращения населения. Проведенный анализ позволил сделать ряд выводов.

1. Не наблюдаются сколько-нибудь существенные разрывы или градиенты в происходящих процессах динамики расселения. Зоны положительной и отрицательной динамики расселения трансграничны и симметричны по обе стороны границы в тех случаях, когда симметричны природные и социально-экономические условия обеих территорий. Так, на востоке Оренбургской области и на прилегающих территориях востока Актюбинской области, а также на территории Акбулакского и Соль-Илецкого районов Оренбургской области и прилегающих территориях Актюбинской и Западно-Казахстанской областей со схожим неблагоприятным географическим положением сформировались фактически единые кластеры отрицательной динамики расселения населения и сокращения его численности.

2. На территориях, протягивающихся вдоль оси Оренбург-Уральск, формируется фактически единая сплошная зона положительной динамики расселения и роста населения, связанная с преимуществами ее географического положения.

3. На невысокую, вопреки распространенному мнению, барьерную функцию границы указывает и то, что создаваемый влиянием Уральска кластер «горячих» точек населенных пунктов распро- 
страняется и на территорию Первомайского района Оренбургской области без каких-либо искажений и разрывов.

4. Асимметричные по отношению к границе кластеры связаны не с ее влиянием, а являются следствием эксцентрично расположенных относительно границы городов (Актобе, Аксай, Оренбург), которые выступают главными «концентраторами» населения.

\section{ЗАКЛЮЧЕНИЕ}

Таким образом, проведенное нами на примере российско-казахстанской границы исследование указывает на то, что возникшее четверть века назад новое российское приграничье не оказывает выраженного угнетающего воздействия на систему расселения населения. Кроме того, происходящие в расселении процессы, как правило, трансграничны.

Анализ влияния границы на расселение населения, результаты которого представлены выше, авторы рассматривают как пилотный. Исследование планируется продолжить в дальнейшем, расширив, прежде всего, его территориальные рамки.

\section{СПИСОК ЛИТЕРАТУРЫ}

1. Бакланов П.Я., Ганзей С.С. Приграничные и трансграничные территории как объект географических исследований // Известия РАН. Серия географическая, 2004, № 4, с. 27-34.
2. Михель Е. А. Влияние глобализации мировой экономики на трансграничные трудовые миграции населения в приграничном регионе: на примере Республики Карелия // Региональная экономика: теория и практика, 2008, № 31, с. 22-24.

3. Соколов А. А. Территориальный анализ размещения и сдвигов населения в степной зоне России // Becтник Воронежского государственного университета. Серия География. Геоэкология, 2016, № 1, с. 24-29.

4. Сухнев В. Ю. Пролив Измены: почему нельзя «отдавать» Курилы // Стратегия России, 2019, №9, c. $65-78$.

5. Трансграничные миграчии и принимающее общество: механизмы и практики взаимной адаптации. Научный редактор В. И. Дятлов. Екатеринбург, издательство Уральского университета, 2009. 394 с.

6. Чибилев А.А. (мл.), Семенов Е.А., Григоревский Д. В. Проблемы и специфика сельского расселения в Оренбургской области // Вестник Воронежсккого государственного университета. Серия География. Геоэкология, 2016, № 1, с. 34-38.

7. Manakov A. The influence of the border position of the Pskov region on the socio-cultural values of the population // Research reports, 2010, no. 2, pp. 99-107.

8. Pociute G., Daugirdas V. The border's influence on peripherality: case study of the Lithuanian-Belarusian border region // Region and regionalism, 2013, no. 2, pp. 175-195.

Конфликт интересов: Авторы декларируют отсутствие явных и потенциальных конфликтов интересов, связанных с публикацией настоящей статьи.

Поступила в редакиию 11.11.2019 Принята к публикации 02.06.2020 


\title{
Population Resettlement Dynamics in the Russian-Kazakh Border Zone
}

\author{
R.Sh. Akhmetov ${ }^{1}$, I. Y. Filimonova ${ }^{2} \bowtie$, N. I. Akhmetova ${ }^{3}$ \\ ${ }^{1}$ Orenburg State University, Russian Federation \\ (13, Pobedy Ave., Orenburg, 460018) \\ ${ }^{2}$ Institute of the steppe of the Ural branch of the Russian Academy of Sciences - a separate structural unit of \\ the Federal State Budgetary Institution of Science Orenburg Federal Research Center of the Ural Branch of \\ the Russian Academy of Sciences, Russian Federation \\ (11 Pionerskaya St., Orenburg, 460000) \\ ${ }^{3}$ Orenburg State Pedagogical University, Russian Federation \\ (19, Sovetskaya St., Orenburg, 460014)
}

\begin{abstract}
The purpose of the article was the impact of new state borders, which arose because of the USSR collapse, on the study of population settlement process on both sides of the state border.

The information base of the research was the uniform geographical database of the population censuses on the territory of the Orenburg region and the Kazakhstan cross-border regions. Comparative analysis showed a significant similarity in the dynamics of these indicators between the frontier zone and the territory of the region as a whole. The results of the study did not support the expected outflow of population from the frontier zone and the "skeletization" of the settlement pattern network as a result of the barrier function of the state border and, consequently, the deterioration of economic activity conditions and the difficulties of social contacts. A number of major cities, the main rivers of the region and other attractive objects for settlement minimized and masked border effect. Thus, on the example of the Russian-Kazakhstan border the study indicates that the new Russian frontier zone does not have a marked oppressive effect on the population settlement pattern. In addition, the processes occurring in the settlement on both sides of the state border are, as a rule, similar and transfrontier.
\end{abstract}

Key words: population settlement pattern, settlement pattern dynamics, frontier zones.

Funding: The work was performed as part of the state assignment AAAA-A17-117012610022-5.

For citation: Akhmetov R. Sh., Filimonova I. Y., Akhmetova N. I. Population Resettlement Dynamics in the Russian-Kazakh Border Zone. Vestnik Voronezskogo gosudarstvennogo universiteta. Seria Geografia. Geoekologia, 2020, No. 2, pp. 29-34. (In Russ.) DOI: https://doi.org/10.17308/geo.2020.2/2882

\section{REFERENCES}

1. Baklanov P.Ya., Ganzey S.S. Prigranichnye i transgranichnye territorii kak ob"ekt geograficheskikh issledovaniy [Border and cross-border territories as an object for geographical research]. Izvestiya RAN. Seriya geograficheskaya, 2004, no. 4, pp. 27-34. (In Russ.)

2. Mikhel' E. A. Vliyanie globalizatsii mirovoy ekonomiki na transgranichnye trudovye migratsii naseleniya v prigranichnom regione: na primere Respubliki Kareliya [The impact of global economic globalization on crossborder labor migration in the border region: the case of the Republic of Karelia]. Regional'naya ekonomika: teoriya $i$ praktika, 2008, no. 31, pp. 22-24. (In Russ.)
3. Sokolov A. A. Territorial'nyy analiz razmeshcheniya i sdvigov naseleniya v stepnoy zone Rossii [Territorial analysis of population distribution and shifts in the Russian steppe zone]. Vestnik Voronezskogo gosudarstvennogo universiteta. Seria Geografia. Geoekologia, 2016, no. 1, pp. 24-29. (In Russ.)

4. Sukhnev V. Yu. Proliv Izmeny: pochemu nel'zya "otdavat"' Kurily [The Strait Of Infidelity: why it is impossible to "give away" the Kurils]. Strategiya Rossii, 2019, no. 9, pp. 65-78. (In Russ.)

5. Transgranichnye migratsii i prinimayushchee obshchestvo: mekhanizmy i praktiki vzaimnoy adaptatsii. Nauchnyy redaktor V. I. Dyatlov [Cross-Border migration and host society: mechanisms and practices of mutual adaptation]. Yekaterinburg: Ural University press. 394 p. (In Russ.)

(C) Akhmetov R.Sh., Filimonova I. Y., Akhmetova N.I., 2020

E-mail: filimo-irina@yandex.ru

cc) (i) The content is available under Creative Commons Attribution 4.0 License. 
6. Chibilev A.A. (ml.), Semenov E.A., Grigorevskiy D. V. Problemy i spetsifika sel'skogo rasseleniya v Orenburgskoy oblasti [Problems and specifics of rural settlement in the Orenburg region]. Vestnik Voronezskogo gosudarstvennogo universiteta. Seria Geografia. Geoekologia, 2016, no. 1, pp. 34-38. (In Russ.)

7. Manakov A. The influence of the border position of the Pskov region on the socio-cultural values of the population. Research reports, 2010, no. 2, pp. 99-107.

\section{Ахметов Ренат Шамильевич}

кандидат географических наук, доцент, доцент кафедры географии и регионоведения Оренбургского государственного университета, г. Оренбург, Российская Федерация, ORCID: https://orcid.org/0000-0003-0731-3256, e-mail: renat262@gmail.com

Филимонова Ирина Юрьевна

кандидат географических наук, доцент, научный сотрудник Института степи Уральского отделения Российской академии наук - обособленного структурного подразделения Федерального государственного бюджетного учреждения науки Оренбургский федеральный исследовательский центр Уральского отделения Российской академии наук, г. Оренбург, Российская Федерация, ORCID https://orcid.org/0000-0002-9773-2173, e-mail: filimo-irina@yandex.ru

Ахметова Надежда Ивановна

старший преподаватель кафедры доцент кафедры географии и методики преподавания географических дисциплин, Оренбургского государственного педагогического университета, г. Оренбург, Российская Федерация, ORCID https://orcid.org/0000-0003-4641-0753, e-mail: nad65@list.ru
8. Pociute G., Daugirdas V. The border's influence on peripherality: case study of the Lithuanian-Belarusian border region. Region and regionalism, 2013, no. 2, pp. 175-195.

Conflict of interests: The authors declare no information of obvious and potential conflicts of interest related to the publication of this article.

Received: 11.11.2019

Accepted: 02.06.2020

Renat Sh. Akhmetov

Cand. Sci. (Geogr.), Associate Professor, Associate Professor of the Department of Geography and Regional Studies, Orenburg State University, Orenburg, Russian Federation, ORCID: https://orcid.org/0000-0003-0731-3256, e-mail: renat262@gmail.com

Irina Yu. Filimonova

Cand. Sci. (Geogr.), Associate Professor, Research Associate of the Steppe Institute of the Ural branch of the Russian Academy of Sciences - a separate structural division of the Federal state budgetary institution of science Orenburg Federal research center of the Ural branch of the Russian Academy of Sciences, Orenburg, Russian Federation, ORCID: https://orcid.org/0000-0002-9773-2173, e-mail: filimo-irina@ yandex.ru

Nadezhda I. Akhmetova

Senior Lecturer of the Department, Associate Professor of the Department of Geography and Methods of Teaching Geographical Disciplines, Orenburg State Pedagogical University, Orenburg, Russian Federation, ORCID: https://orcid.org/0000-0003-4641-0753, e-mail: nad65@ list.ru 